To seek creative solutions to some of these problems, the United Nations Development Program, with the help of many other organizations and major financial support from the Government of Korea, has created the International Vaccine Institute (IVI). This research center will be headquartered in new buildings on the campus of Seoul National University in Korea and will provide assistance to individuals and institutions in the developing world, so that they may become active participants in the evolutionary process that is reshaping the vaccine enterprise. The constitution of IVI (http://www.ivi.org), embedded in a United Nations-sponsored international agreement, has been signed by more than 30 countries and the World Health Organization and was ratified in 1997.

Is protection from diseases that can be prevented by vaccination a universal human right? If the answer is even partially yes, we must look for ways to ensure that a reasonable minimum level of access, affordability and equity for essential vaccines is provided for all. The transformations now taking place at the global level are inevitable. So will be the demand to find realistic solutions to address the legitimate needs of developing nations. The solutions must be acceptable to both the public and the private sectors, and to both the developed and the developing worlds.
1. Plotkin, S.L. \& Plotkin, S.A. A short history of vaccination. In Vaccines. (eds. Plotkin, S.A. \& Mortimer, E.A.) pages 1-11 (W.B. Saunders Co., New York, 1994).

2. Shin, S. \& Shahi, G.S. Vaccine production in developing countries. In Vaccination and World Health. (eds. Cutts, F.T. \& Smith, P.G.) pages 39-60 (John Wiley and Sons, Chichester, 1995).

3. Muraskin, W. The war against hepatitis B: A history of the International Task Force on Hepatitis B Immunization. (University of Pennsylvania Press, Philadelphia, 1995).

4. Jayaraman, K.S. India to develop its own AIDS vaccine. Nature Med. 4, 7 (1998).

5. Bloom, B.R. The highest attainable standard: Vexed ethical issues in AIDS vaccines. Science 279, 186-188, 1998.

International Vaccine Institute Seoul National University Campus Shillim-Dong, Kwanak-Ku, Seoul, Korea email: sishin@plaza.snu.ac.kr

\title{
Recruiting HLA to fight HIV
}

\section{HLA-restricted peptides from HIV-resistant individuals may act as guides to immunogenic regions of viral proteins.}

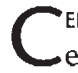
ERTAIN INDIVIDUALS, WHO are consistently exposed to the human immuno-deficiency virus (HIV), do not succumb to infection $^{1,2}$. The factors responsible for HIV resistance fall into two groups: protective mutations in chemokine co-receptors ${ }^{3}$ and the presence of certain allelic specificities of the histocompatibility complex such as HLA-A28 (ref.4). The protection conferred by particular HLA alleles is induced by the corresponding HLA-restricted peptides. These peptides may serve as guides to the identification of the immunogenic regions of HIV proteins, an important step in vaccine development.

The HLA genes involved in processing, transport and presentation of peptides are polymorphic resulting in the presentation

\section{BARBARA LAUMBACHER \& RUDOLF WANK}

of different peptides in individuals infected with the same virus (see figure). Analysis of Kenyan and Gambian prostitutes continually exposed to HIV, who remained HIVseronegative and PCR-negative for reverse transcriptase, revealed a strong cytotoxic $\mathrm{T}$ cell immune response against various HIV peptides associated with HLA-A28 and HLA-B35 (refs 4,5). HLA-A28 is also protective in Caucasians (R. Wank, unpublished). Sequence-based typing indicates that the alleles $A^{*} 68012$ and $A^{*} 6802$ are associated with HIV resistance whereas $A^{*} 68011$ is not.

It should be possible to identify the different HIV peptides that are presented in the context of $A^{\star} 68012$ and $A^{\star} 6802$. The viral regions marked by these 'pilot' peptides can then be evaluated for their capacity to

UNAVAILABLE
FOR
COPYRIGHT
REASONS

\footnotetext{
Viral proteins are degraded to different peptides by the proteasome subunits, LMP2/7. Variants of the transporters TAP1 and TAP2 bind different peptides and translocate them to the endoplasmic reticulum (ER), where they become incorporated into HLA molecules. The HLA-selected peptides are then presented on the cell surface.
}

prime $\mathrm{T}$ lymphocytes. Identification of virus-derived, HLA-restricted 'pilot' peptides from individuals who are immune to a specific virus has potential for the development of vaccines against many viral diseases. That such an approach might work is suggested by data from cancer vaccine studies. HLA-restricted peptides of the E7 protein of human papilloma virus, which stimulate a strong $\mathrm{T}$ cell response, have been used in a vaccine to protect mice against cervical cancer ${ }^{7}$.

1. Shearer, G.S. \& Clerici, M. Protective immunity against HIV infection: Has nature done the experiment for us? Immunol. Today 17, 21-24 (1996).

2. Rowland-Jones, S.L. \& MCMichael, A. Immune responses in HIV-exposed seronegatives: Have they repelled the virus? Curr. Opin. Immunol. 7, 448-455 (1955).

3. Biti R., French R.F., Young B., Stewart G. \& Liang T. HIV infection in an individual homozygous for the CCR5 deletion allele. Nature Med. 3, 252-253 (1997).

4. Plummer, F.A. et al. Evidence of resistance to HIV among continuously exposed prostitutes in Nairobi, Kenya. Proceedings of the VIII International conference on AIDS (Berlin) 1, 23, abstr. \#WS-A4073 (1993).

5. Rowland-Jones S. et al. HIV-specific cytotoxic T cells in HIV-exposed but uninfected Gambian women. Nature Med. 1, 59-71 (1995).

6. Plummer, F.A. et al. Cellular immune responses correlate with protection against HIV-1 among women resistant to infection. Proceedings of the IX International Conference on AIDS (Kampala) 1,140, abstr. \#WeA189 (1995).

7. Ressing, M.F. et al. Occasional memory cytotoxic T cell responses of patients with HPV16-positive cervical lesions against a human leukocyte antigen $A^{\star} 0201$-restricted E7 encoded epitope. Cancer Res. $56,582-588$ (1996)

\section{Institut fur Immunologie}

Universitat Munchen

D-80336 Munchen, Germany

wank@ifi.med.uni-muenchen.de 